\title{
1 TITLE
}

2 The impact of previous hamstring strain injury on the change in eccentric hamstring strength

3 during pre-season training in elite Australian footballers.

4

5

6

7

8

9

10

11

12

13

14

15

16

17

18

19 
ABSTRACT

Background: Hamstring strain injuries (HSIs) are the most common injury type in Australian football and the rate of recurrence has been consistently high for a number of years. Long lasting neuromuscular inhibition has been noted in previously injured athletes but it is not known if this influences athletes adaptive response to training. Purpose: To determine if elite Australian footballers with a prior unilateral HSI (previously injured group) display lesser improvements in eccentric hamstring strength during pre-season training compared to athletes without a history of HSI (control group). Study design: Prospective cohort study. Methods: Ninety-nine elite Australian footballers participated (17 with a history of unilateral HSI in the previous 12 month period). Eccentric hamstring strength was assessed at the start and end of pre-season training using an instrumented Nordic hamstring device. Change in eccentric strength across preseason was determine in absolute terms and normalised to start of preseason strength. Start of preseason strength was used as a covariate to control for differences in starting strength. Results: The left and right limbs in the control group showed no difference in absolute or relative change (left limb absolute change, $60.7 \pm 72.9 \mathrm{~N}$; relative change, $1.28 \pm 0.34$; right limb absolute change, $48.6 \pm 83.8 \mathrm{~N}$; relative change, $1.24 \pm 0.43)$. Similarly, the injured and uninjured limbs from the previously injured group showed no difference for either absolute or relative measures of change (injured limb absolute change, $13.1 \pm 57.7 \mathrm{~N}$; relative change, $1.07 \pm 0.18$; uninjured limb absolute change, $14.7 \pm 54.0 \mathrm{~N}$; relative change, $1.07 \pm 0.22 \mathrm{~N})$. The previously injured group displayed a significantly lesser increase in eccentric hamstring strength across the preseason (absolute change, $13.9 \pm 55.0$; relative change, $1.07 \pm 0.20$ ) compared to the control group (absolute change, $54.6 \pm 78.5$; relative change, $1.26 \pm 0.39$ ) for both absolute and relative measures $(\mathrm{p}<0.001)$, even after controlling for differences in start of pre-season eccentric hamstring strength, which had a significant effect on strength improvement. Conclusion: Elite Australian footballers with a unilateral HSI history displayed lesser improvements in eccentric hamstring strength across preseason training. The smaller improvements were not restricted to the previously injured limb as the contralateral limb also displayed similarly small improvements in eccentric strength. Whether this is the cause of or the result of injury remains to be seen, but it has the potential 
49 Key terms: Hamstring, muscle injury, eccentric strength, Nordic hamstring exercise.

50 What is known about the subject: The rate of recurrence of hamstring strain injuries in elite

51 Australian footballers has been high for a number of years, however the reason for this remains

52 largely unknown. There is an increasing evidence base of prolonged deficits in neuromuscular

53 function in previously injured hamstrings. What remains to be seen is whether previously injured

54 athletes exhibit a muted adaptive response to training interventions.

What this study adds to the existing knowledge: This study looked specifically at changes in eccentric hamstring strength across preseason training, due to the important role of eccentric strength in preventing hamstring strain injury. Previously injured Australian footballers with a history of hamstring strain injury displayed smaller improvements in eccentric hamstring strength across preseason compared to uninjured controls. This study draws to attention the possibility that previously injured athletes may have long term restrictions in strength improvements even after 'successful' rehabilitation and return to play.

\section{INTRODUCTION}

Over the past 20 seasons hamstring strain injuries (HSIs) have been the most prevalent injury in Australian football ${ }^{18}$ and they impose a significant financial burden on athletes and their associated clubs. ${ }^{9}$ Whilst the rate of recurrent HSIs in the elite Australian Football League has fallen in recent years ${ }^{17}$ it still remains one of the most common types of injury for recurrence. ${ }^{18}$ In Australian football, much like other sports, ${ }^{18}$ history of HSI is repeatedly identified as the primary risk factor for future injury ${ }^{625}$ and is often considered a non-modifiable risk factor (i.e. it cannot be changed). ${ }^{14}$ 
However, a growing body of evidence indicates that neuromuscular maladaptations associated with previous HSI may be responsible for the elevation of future injury risk, despite return to play and 'successful' rehabilitation. ${ }^{15162122}$ Most notably, hamstrings which have previously sustained a strain injury display signs of neuromuscular inhibition during eccentric contractions, when compared to the contralateral uninjured hamstring. ${ }^{15} 1622$ The resultant deficits in eccentric knee flexor strength might reasonably be expected to increase the likelihood of future HSI in this limb, given lower levels of eccentric hamstring strength increases the risk of future injury. ${ }^{423}$

81 A recent review ${ }^{5}$ proposed a novel framework suggesting that persistent neuromuscular inhibition during eccentric contraction following HSI $^{151622}$ could lead to continued eccentric weakness and thus elevated risk of re-injury. ${ }^{14}$ Based on the proposed framework, it would be expected that this inhibition has the potential to limit the extent of muscular adaptations in response to rehabilitative and prophylactic exercises, given the need for high levels of activation to drive adaptation. ${ }^{514}$ If this were the case, athletes with a previous HSI might not only show deficits in eccentric hamstring strength in the previously injured limb but may also show a suppressed response to eccentric training interventions that are commonly utilised in prophylactic programs. The impact of a prior HSI on the adaptive capacity of a previously injured athlete is, however, yet to be examined.

In the elite Australian Football League the pre-season training period spans up to 4 months between November and February. ${ }^{24}$ It is a time in the training cycle where teams focus on increasing physical fitness with an aim to improve performance and avoid injury. ${ }^{24}$ From the perspective of preventing HSI, it is common to target gains in eccentric hamstring strength as one of the major outcomes during the pre-season period. Much of this philosophy is based on evidence showing the preventative benefits of eccentric hamstring strengthening during pre-season in other sports. ${ }^{2419}$ There is currently no work which examines the improvements in eccentric hamstring strength throughout the pre-season training period in elite Australian footballers and whether previous HSI impacts upon the athlete's ability to improve eccentric hamstring strength. 
The purpose of this investigation was to assess eccentric hamstring strength changes during the preseason training period in elite Australian footballers with and without a history of unilateral HSI. We hypothesised that athletes with a history of HSI would exhibit a minimal increase in eccentric hamstring strength during the pre-season training period compared to the uninjured athletes.

\section{MATERIALS \& METHODS}

\section{Sample size calculations}

Based on a previous study, ${ }^{22}$ that used a similar research design, a priori sample size of 15 for the previously injured group and 75 for the control group was determined using $G^{*}$ Power (version 3.1.7).

The input parameters for the power analysis were: independent t-test; effect size $(d)=0.8 ; \alpha=0.05 ; \beta$ $=0.20$ and allocation ratio 5:1. An independent t-test was selected since the change in eccentric hamstring strength for both limbs was expected to be averaged and then compared between groups, as performed previously, ${ }^{22}$ given that the adaptive capacity would be centrally impaired and not limb specific. ${ }^{5}$ A large effect size was anticipated based on Rhea et al., ${ }^{20}$ and the $5: 1$ sample ratio was based on typical hamstring injury rates at $15-20 \%{ }^{14}$

\section{Participants}

A total of 99 Australian footballers from five elite teams were eligible to participate (from an overall pool of 210) in the study, of which 17 had a history of unilateral HSI (previously injured group), confirmed by magnetic resonance imaging (MRI), in the previous 12 month period. All participants were free of injury to the lower limbs (able to participate fully in training) that would be expected to influence knee flexor strength at the time of testing. Exclusion criteria included: any athlete with a history of bilateral HSI in the prior 12 months, any athlete with a history of clinical diagnosed HSI that was negative on MRI in the prior 12 months, any athlete who sustained a HSI during pre-season, any athlete who had sustained an anterior cruciate ligament rupture previously or who had sustained an injury to the quadriceps, calf or groin/hip in the prior 12 months. All testing procedures were approved by the University Human Research Ethics Committee and participants gave informed written consent prior to testing after having all procedures explained to them. 


\section{Experimental design}

126 The current study employed a prospective cohort design. All athletes reported for testing during the

127 first and final weeks of preseason training (November through February). On each occasion all athletes completed a submaximal warm up set of the Nordic hamstring exercise, followed by a single set of three maximal repetitions of the Nordic hamstring exercise, during which left and right limb eccentric knee flexor forces were recorded using a custom made device. All testing was performed following similar levels (duration and intensity) of training completed in the days prior.

\section{Eccentric knee flexor strength assessment}

The device, used to determine eccentric knee flexor strength during the Nordic hamstring exercise, and its reliability, have been described previously, and can be seen in Figures 1 and $2 .{ }^{13}$ Participants knelt on a padded board, with the ankles secured immediately superior to the lateral malleolus by individual ankle braces which were attached to custom made uniaxial load cells (Delphi Force Measurement, Gold Coast, Australia) with wireless data acquisition capabilities (Mantracourt, Devon, UK). The ankle braces and load cells were secured to a pivot which allowed the force to always be measured through the long axis of the load cells, with an individual load cell for both the left and right limb allowing for separate measures from each limb. Following a warm up set, participants performed one set of three maximal repetitions of the bilateral Nordic hamstring exercises. Instructions to players were to gradually lean forward at the slowest possible speed while maximally resisting this movement with both limbs while keeping the trunk and hips held in a neutral position throughout, and the hands held across the chest. ${ }^{13}$ Participants were loudly exhorted to provide maximal effort throughout each repetition. A trial was deemed acceptable when the force output reached a distinct peak (indicative of maximal eccentric strength), followed by a rapid decline in force which occurred when the athlete was no longer able to resist the effects of gravity acting on the segment above the knee joint.

\section{Injury histories}

For all athletes recruited who had sustained a unilateral HSI in the 12 months prior to the first testing session, details of their injury history was obtained from their club clinician. Details obtained included 
which limb was injured (dominant/non dominant limb), muscle injured (biceps femoris long

152 head/biceps femoris short head/semimembranousus/semitendinosus), location of injury

153 (proximal/distal, muscle belly/muscle-tendon junction), activity type performed at time of injury (i.e.

154 running/kicking etc.) and grade of injury (I, II or III). Importantly, all diagnoses were confirmed by

155 MRI performed 48-72 hours after the insult.

\section{Pre-season training programs}

With regards to prophylactic programs for the prevention of HSIs all clubs utilised the Nordic hamstring exercise and stiff legged (or Romanian) deadlift as part of their training regimen. Typical set and repetition ranges for the Nordic hamstring exercise were 2-4 sets for 6-10 repetitions. These prophylactic exercises were completed at least on a weekly basis by all teams included in the study. In addition there was a strong focus on exercises that aimed to increase eccentric hamstring strength using a combination of bilateral and unilateral movements. Often athletes with a history of previous HSI were prescribed additional eccentric exercise as part of efforts to further reduce their risk of reinjury.

\section{Data analysis}

Force data for both limbs during the Nordic hamstring exercise was logged to a personal computer at $100 \mathrm{~Hz}$ through a wireless USB base station receiver (Mantracourt, Devon, UK). For both limbs (left/right for the control group or injured/uninjured for the previously injured group) peak force for each contraction was determined and maximal force generating capacity was expressed as an average of the peak from three contractions (average peak force). This method of analysis was chosen because

171 it has displayed high test-retest reliability (intraclass correlation coefficients, 0.85 to 0.89 ). ${ }^{13}$ The

172 change in eccentric strength across pre-season was expressed in absolute units (Newtons) as well as

173 relative to the early preseason strength measure by taking the quotient of late preseason and early preseason strength. 
Data were screened and all test assumptions assessed to confirm the appropriateness of the analyses.

177 The change in eccentric hamstring strength across preseason was compared between the left and right

178 limbs of the control group and between the retrospectively injured and uninjured limbs in the previously injured group using a two-tailed paired samples t-test. As no within group differences were noted, the two limbs for each group were averaged. To compare between the control and previously injured groups a univariate general linear model was employed with eccentric knee flexor strength at the start of preseason used as a covariate to control for differences in baseline strength since it was different between groups. Statistical significance was set at $\mathrm{p}<0.05$ and Cohen's $d$ used to assess the magnitude of the effect. Data are reported as mean differences \pm standard deviations or, if stated, 95\% confidence interval $(95 \% \mathrm{CI})$. All statistical analyses and assumption testing was performed using SPSS version 19.0.0.1 (IBM Corporation).

\section{RESULTS}

Of the 17 athletes with a history of unilateral HSI in the prior 12 months, the injuries were distributed accordingly: dominant limb (53\%), biceps femoris long head (76\%) and the proximal muscle-tendon junction (53\%) (Table 1). Time since the most recent HSI ranged from 1.5 to 12 months (median time since injury, 4.4 months/19 weeks), with the rehabilitation time ranging from 19 to 79 days (median rehabilitation time, 31 days). The distribution of these 17 athletes at each of the five participating club was five, four, four, three and one athlete/s respectively. All athletes (and associated medical staff) reported a strong emphasis on eccentric conditioning and high speed running during late stage rehabilitation and in the lead up to return to play.

Descriptive statistics for both groups with respect to demographic data and absolute levels of eccentric hamstring strength at the start and end of preseason can be found in Table 2. Whilst the previously injured athletes presented with generally higher level of eccentric strength compared to the control group, the only significant differences was the left limb from the control group was weaker than the uninjured limb in the previously injured $\operatorname{limb}(\mathrm{p}=0.020)$ With respect to the change in eccentric hamstring strength across pre-season, the left and right limbs in the control group showed no 
difference in either absolute or relative measures of change (left limb absolute change, $60.7 \pm 72.9 \mathrm{~N}$; relative change, $1.28 \pm 0.34$; right limb absolute change, $48.6 \pm 83.8 \mathrm{~N}$; relative change, $1.24 \pm 0.43$ )

(Table 3). Similarly, the injured and uninjured limbs from the previously injured group showed no difference in either absolute or relative measures of change (injured limb absolute change, $13.1 \pm 57.7 \mathrm{~N}$; relative change, $1.07 \pm 0.18$; uninjured limb absolute change, $14.7 \pm 54.0 \mathrm{~N}$; relative change, $1.07 \pm 0.22 \mathrm{~N})$ (Table 3).

Given that there were no differences in the change in eccentric hamstring strength between the left and right limb in the control group (left vs right; absolute change $\mathrm{p}=0.06, d=0.15$, relative change, $\mathrm{p}$ $=0.29, \mathrm{~d}=0.10)$ the responses of the two limbs were averaged to give a mean control group change in eccentric hamstring strength. Similarly, for the previously injured group, as there was no difference between limbs (injured vs uninjured; absolute change, $\mathrm{p}=0.88, d=0.03$, relative change, $\mathrm{p}=0.93, \mathrm{~d}$ $=0.00)$ the responses of the injured and uninjured limbs were also averaged to give a mean injured group change in eccentric hamstring strength. The previously injured group displayed a significantly smaller increase in eccentric hamstring strength across the preseason (absolute change, 13.9 \pm 55.0 ; relative change, $1.07 \pm 0.20$ ) compared to the control group (absolute change, $54.6 \pm 78.5$; relative change, $1.26 \pm 0.39$ ) for both absolute and relative measures, even after controlling for differences in start of pre-season eccentric hamstring strength. Start of pre-season eccentric hamstring strength had a significant effect $(\mathrm{p}<0.001)$ on both change in absolute and relative strength changes (Table 4$)$.

\section{DISCUSSION}

The present study aimed to determine if elite Australian footballers with a history of unilateral HSI (within the prior 12 months) would display a smaller increase in eccentric hamstring strength across the pre-season training period compared to athletes without a history of HSI. The major finding was that the previously injured athletes displayed smaller increases in eccentric hamstring strength compared to the control group athletes, who had no history of HSI in the prior 12 months. Interestingly, the smaller increase in eccentric strength across pre-season was not restricted to the 
previously injured limb, as the injured and uninjured limb strength increases did not differ.

230 This study is, to the authors' knowledge, the first to examine the change in eccentric hamstring strength across the pre-season training period in elite Australian footballers. One paper, a randomised control trial (RCT) in elite Swedish soccer players, has examined the impact of augmented eccentric training, via flywheel ergometer, for the hamstrings across 10 weeks of preseason training and reported a $\sim 19 \%$ increase in eccentric hamstring torque. ${ }^{2}$ The improvements in the control group in the present study is similar in magnitude (15-20\%) to those reported by Askling et al. $(2003)^{2}$ in the training arm of their trial, however the impact of previous HSI on eccentric strength improvements was not examined.

The finding that athletes, with a history of HSI, displayed a smaller increase in eccentric strength during pre-season might have implications for recurrent injuries. Given the retrospective nature of these observations it is impossible to determine whether a lesser increase in eccentric strength is the result of injury and/or a predisposing factor that lead to the initial insult. It is also possible that a heavy focus on eccentric exercise during the late stage of rehabilitation could influence the change in eccentric hamstring strength during the subsequent preseason training period. Regardless, given the established link between prior HSI and increased risk of future injury in elite Australian football, ${ }^{625}$ characteristics of previously injured athletes can help to identify variables that warrant further investigation. Of interest, from the current dataset, is the possibility that athletes display variable increases in eccentric hamstring strength (i.e. high and low responders, respectively) across preseason training. As eccentric strengthening interventions ${ }^{2}{ }^{19}$ and smaller between limb eccentric strength imbalances $^{23}$ appear to reduce the risk of HSI, individuals with a reduced ability to increase eccentric hamstring strength might be predisposed to a greater likelihood of future HSI. Further work should consider the implementation of a standard eccentric hamstring strengthening intervention across a

252 large participant pool to determine the spectrum of strength increases, with these participants followed prospectively to establish if there is a causative relationship with HSI. It should also be acknowledged that rehabilitation processes would likely play a critical role in the recovery of eccentric strength 
following HSI and might also influence the adaptive response to eccentric exercise. It would be of interest to examine increases in eccentric strength and adaptive capacity in previously injured athletes who are exposed to standardised rehabilitation protocols, such as those reported previously. ${ }^{3}$ It is also intriguing that the injured athletes displayed smaller increases in eccentric strength across preseason but, there was no difference noted between the injured and uninjured limbs within this group. This raises the possibility that the persistent neuromuscular inhibition noted during eccentric contraction following unilateral HSI, ${ }^{151622}$ may be mediated by central mechanisms and as such has bilateral effects. Furthermore, it is possible that differences between the injured and control groups, with respect to eccentric hamstring strength at the start of preseason (i.e. baseline strength), may have impacted on the improvements seen in strength across preseason. It might be argued that the higher starting strength in the injured group would limit their scope for improvement across pre-season, however on-going subsequent work from our group suggests that $\sim 340 \mathrm{~N}$ is not close to a maximal strength capacity of most elite Australian footballers, with scores well in excess of $400 \mathrm{~N}$ noted in well trained athletes. When start of preseason eccentric strength was controlled for, as a covariate in the analysis, differences between the groups still persisted. .It should also be noted that when examining the increase in eccentric hamstring strength in athletes from both groups in the bottom quartile for eccentric strength at the start of preseason, the control group athletes (average start preseason strength $195 \mathrm{~N}$ ) displayed a $\sim 55 \%$ increase in eccentric strength compared to the previously injured group (average start preseason strength 194N) which increased $\sim 20 \%$.

The suppression of eccentric hamstring strength gains in the previously hamstring strain injured athlete, as reported in the current study, is intriguing as a large RCT has shown that the implementation of the Nordic hamstring exercise during preseason in soccer players resulted in a significant reduction in the rate of reinjury. ${ }^{19}$ It would be reasonable to posit that the significant reduction in reinjuries was conferred by an increase in eccentric hamstring strength following the Nordic hamstring exercise intervention ${ }^{12}$. The results from the current study suggest that eccentric strength improvements may have been restricted in the previously injured athletes, however the cohort from the $\mathrm{RCT}^{19}$ consisted of soccer players without a history of eccentric training of the hamstrings 
prior to the intervention, which differs significantly from elite Australian footballers who employ targeted eccentric exercise, as part of the late stages of rehabilitation and return to play, and generally for prevention of HSI. It remains to be seen if greater magnitudes of, or larger improvements in, eccentric hamstring strength, assessed during the performance of the Nordic hamstring exercise, reduces risk of future HSI.

Besides a history of unilateral HSI, other factors may be responsible for the divergent responses between the two groups. Firstly, the strong focus on eccentric exercise during the late stages of rehabilitation has the potential to influence eccentric strength and the change in strength across the preseason period. Indeed, the lack of a between limb strength imbalance in the previously injured group at the start of preseason (1.3\%), which was much lesser than previous reports using the current strength assessment device $(15 \%)^{13}$, is suggestive that rehabilitation in this cohort aimed to minimise any deficits in eccentric strength. The influence of rehabilitation procedures, across the spectrum of HSI severities, on long-lasting deficits in function and response to training stimulus is an area of great interest for future investigations. Secondly, the physiological demands of Australian football require athletes at the elite level to possess high aerobic and anaerobic fitness, maximal sprint speed, repeatsprint performance and strength and power qualities. ${ }^{7}$ These diverse demands require an intense training load for athletes, particularly during preseason training. However speculative, it is possible that the multiple physiological demands of preseason training might minimise improvements in certain performance markers in some athletes. ${ }^{10}$ If some athletes struggle to improve strength/power qualities (such as eccentric hamstring strength), then it would be reasonable to suggest that their risk of HSI would be greater. ${ }^{4}$ It is possible, that the athletes from the previously injured group in the current work had, in prior seasons, improved eccentric hamstring strength minimally due to the competing demands of preseason training, predisposing them to injury, and that phenomena (a low responder to strength training) was measured here more so than the impact of prior injury. The complex interaction of the numerous factors that can impact on strength gains during preseason training in elite athletes certainly requires greater focus, particularly given the important role strength plays in injury prevention. ${ }^{11}$ 
There are some limitations inherent to this study. The investigators had no control over the pre-season training programs of any team involved (as is to be expected in an elite sporting environment), as this study was purely observational. Whilst we were able to report general details of the pre-season HSI prophylactic program, we are not able to make comment as to whether differing training programs between individuals and/or teams may have influenced the findings. In spite of this, these observations were made on 99 athletes across five elite Australian football teams, suggesting that the results may be generalisable within this sport. Furthermore, HSI history was confined to the previous 12 months to minimise reporting error and this neglects HSIs which occurred prior to this time period. Severe HSIs sustained more than 12 months ago may have confounded the current findings.

Importantly, however, all HSIs were confirmed by MRI to eliminate the inclusion of athletes suffering referred pain posterior thigh injury and this is a strength of the current investigation. ${ }^{25}$ Finally, whilst the study was sufficiently powered to detect between group differences, given the relatively small sample of previously injured athletes, it was underpowered to explore the possible impact of time since injury, the number and severity of previous HSIs, rehabilitation type and length and the possible role of other lower limb injuries on improvements in eccentric hamstring strength across preseason. A larger study examining a more homogenous sample of HSIs, powered to include additional covariates is warranted in future. A larger sample would also allow for analysis to control for cluster effects by team, which was not possible with the current sample size.

In conclusion, elite Australian footballers with a unilateral history of HSI within the previous 12 months display a greater baseline level of and a smaller increase in eccentric hamstring strength through the pre-season training period, compared to their control group counterparts. Interestingly, this diminished response was not confined to the previously injured limb but was also observed in the contralateral uninjured limb, which might suggest that the effects of prior HSI may be centrally mediated. The existence of high and low responders to eccentric exercise and the impact on future HSI risk is worthy of further examination. 
335

336

337

338

339

340

341

342

343

344

345

346

347

348

349

350

351

352

353

354 
1. Arnason A, Sigurdsson SB, Gudmundsson A, Holme I, Engebretsen L, Bahr R. Risk factors for injuries in football. Am J Sports Med. 2004;32(1 Suppl):5-16.

2. Askling C, Karlsson J, Thorstensson A. Hamstring injury occurrence in elite soccer players after preseason strength training with eccentric overload. Scand J Med Sci Sports.

4. Croisier JL, Ganteaume S, Binet J, Genty M, Ferret JM. Strength imbalances and prevention of hamstring injury in professional soccer players: a prospective study. Am J Sports Med. 2008;36(8):1469-1475.

5. Fyfe JJ, Opar DA, Williams MD, Shield AJ. The role of neuromuscular inhibition in hamstring strain injury recurrence. J Electromyogr Kinesiol. 2013;23(3):523-530.

6. Gabbe BJ, Bennell KL, Finch CF, Wajswelner H, Orchard JW. Predictors of hamstring injury at the elite level of Australian football. Scand J Med Sci Sports. 2006;16(1):7-13.

7. Gray AJ, Jenkins DG. Match analysis and the physiological demands of Australian football. Sports Med. 2010;40(4):347-360.

8. Hagglund M, Walden M, Ekstrand J. Previous injury as a risk factor for injury in elite football: a prospective study over two consecutive seasons. Br J Sports Med. 2006;40(9):767772.

9. Hickey J, Shield AJ, Williams MD, Opar DA. The financial cost of hamstring strain injuries in the Australian Football League. Br J Sports Med. 2014; 48(8):729-730.

10. Hickson RC. Interference of strength development by simultaneously training for strength and endurance. Eur J Appl Physiol Occup Physiol. 1980;45(2-3):255-263. 
11. Lauersen JB, Bertelsen DM, Andersen LB. The effectiveness of exercise interventions to prevent sports injuries: a systematic review and meta-analysis of randomised controlled trials. Br J Sports Med. Epub ahead of print. PMID: 24100287

12. Mjolsnes R, Arnason A, Osthagen T, Raastad T, Bahr R. A 10-week randomized trial comparing eccentric vs. concentric hamstring strength training in well-trained soccer players. Scand J Med Sci Sports. 2004;14(5):311-317.

13. Opar DA, Piatkowski T, Williams MD, Shield AJ. A novel device using the Nordic hamstring exercise to assess eccentric knee flexors strength: a reliability and retrospective injury study. $J$ Orthop Sports Phys Ther. 2013; 43(9):636-640.

14. Opar DA, Williams MD, Shield AJ. Hamstring strain injuries: factors that lead to injury and re-injury. Sports Med. 2012;42(3):209-226.

15. Opar DA, Williams MD, Timmins RG, Dear NM, Shield AJ. Knee flexor strength and bicep femoris electromyographical activity is lower in previously strained hamstrings. $J$ Electromyogr Kinesiol. 2012; 23(3):696-703.

16. Opar DA, Williams MD, Timmins RG, Dear NM, Shield AJ. Rate of torque and electromyographic development during anticipated eccentric contraction is lower in previously strained hamstrings. Am J Sports Med. 2013; 41(1):116-125.

17. Orchard J, Seward H. Injury report 2010: Australian football league. Sport Health. 2011;29(2):15.

18. Orchard JW, Seward H, Orchard JJ. Results of 2 decades of injury surveillance and public release of data in the Australian Football League. Am J Sports Med. 2013;41(4):734-741.

19. Petersen J, Thorborg K, Nielsen MB, Budtz-Jorgensen E, Holmich P. Preventive Effect of Eccentric Training on Acute Hamstring Injuries in Men's Soccer: A Cluster-Randomized Controlled Trial. Am J Sports Med. 2011;39(11):2296-2303.

20. Rhea MR, Alvar BA, Burkett LN, Ball SD. A meta-analysis to determine the dose response for strength development. Med Sci Sports Exerc. 2003;35(3):456-464.

21. Silder A, Thelen DG, Heiderscheit BC. Effects of prior hamstring strain injury on strength, flexibility, and running mechanics. Clin Biomech (Bristol, Avon). 2010;25(7):681-686. 
22. Sole G, Milosavljevic S, Nicholson HD, Sullivan SJ. Selective strength loss and decreased muscle activity in hamstring injury. J Orthop Sports Phys Ther. 2011; 41(5):354-63.

23. Sugiura Y, Saito T, Sakuraba K, Sakuma K, Suzuki E. Strength deficits identified with concentric action of the hip extensors and eccentric action of the hamstrings predispose to hamstring injury in elite sprinters. J Orthop Sports Phys Ther. 2008;38(8):457-464.

24. Verrall GM, Slavotinek JP, Barnes PG. The effect of sports specific training on reducing the incidence of hamstring injuries in professional Australian Rules football players. Br J Sports Med. 2005;39(6):363-368.

25. Verrall GM, Slavotinek JP, Barnes PG, Fon GT, Spriggins AJ. Clinical risk factors for hamstring muscle strain injury: a prospective study with correlation of injury by magnetic resonance imaging. Br J Sports Med. 2001;35(6):435-439.

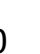

.

1

2

3

\section{6}


432 Figure 1. Performing the Nordic hamstring exercise using the novel device (progressing from 433 left to right). The participant controls the speed of the fall by forceful eccentric contraction of 434 the knee flexors. After the completion of the exercise, the participant slowly returns to the 435 starting position by pushing back up with both hands (not shown). The ankles are secured 436 independently in individual custom-made braces.

437 Figure 2. Close up view of the ankle brace and load cell organisation with participant limb in 438 position during Nordic hamstring exercise. 
453 Table 1: Details of prior hamstring strain injuries sustained by athletes from the injured group

\begin{tabular}{lllllll}
\hline $\begin{array}{l}\text { Participant } \\
\text { number }\end{array}$ & $\begin{array}{l}\text { Limb } \\
\text { injured }\end{array}$ & $\begin{array}{l}\text { Muscle } \\
\text { injured }\end{array}$ & Location of injury & $\begin{array}{l}\text { Activity type at time } \\
\text { of injury }\end{array}$ & $\begin{array}{l}\text { Rehabilitation time for } \\
\text { most recent injury } \\
\text { (days) }\end{array}$ & $\begin{array}{l}\text { Time betv } \\
\text { recent inj } \\
\text { strength } \\
\text { (weeks) }\end{array}$ \\
\hline 1 & & & & & 62 & 14 \\
2 & D & SM & Proximal MTJ & Running & 17 \\
3 & D & BFlh & Distal MTJ & Running & 31 & 31 \\
4 & D & BFlh & Proximal MTJ & Kicking & 76 & 24 \\
5 & ND & ST & Muscle Belly & Running & 25 & 9 \\
6 & ND & BFlh & Proximal MTJ & Running & 19 & 30 \\
7 & ND & SM & Proximal tendon & Bending forward & 79 & 52 \\
8 & D & ST & Distal MTJ & Running & 21 & 32 \\
9 & D & BFlh & Proximal MTJ & Running & 72 & 40 \\
10 & D & BFlh & Muscle belly & Running/kicking & 32 & 25 \\
11 & D & BFlh & Muscle belly & Running & 23 & 35 \\
12 & ND & BFlh & Muscle belly & Not defined & 26 & 16 \\
13 & ND & BFlh & Proximal MTJ & Running & 33 & 19 \\
14 & ND & BFlh & Proximal MTJ & Running & 60 & 12 \\
15 & ND & BFlh & Distal MTJ & Running & 23 & 13 \\
16 & D & BFlh & Proximal MTJ & Bending forward & 35 & 21 \\
17 & ND & BFlh & Proximal MTJ & Running & 19 & \\
\hline
\end{tabular}

454 D, dominant; ND, non-dominant; SM, semimembranosus; BFlh, biceps femoris long head; ST,

455 semitendinosus; MTJ, muscle-tendon junction. 
470 Table 2: Demographic and eccentric knee flexor strength data for athletes with $(n=17)$ and without $471 \quad(\mathrm{n}=82)$ a history of hamstring strain injury in the prior 12 months.

\begin{tabular}{|c|c|c|c|c|c|c|}
\hline \multicolumn{7}{|c|}{ Uninjured group } \\
\hline \multirow[t]{2}{*}{$\begin{array}{l}\text { Age } \\
\text { (years) }\end{array}$} & \multirow[t]{2}{*}{$\begin{array}{l}\text { Height } \\
(\mathrm{cm})\end{array}$} & \multirow[t]{2}{*}{$\begin{array}{l}\text { Weight } \\
(\mathrm{kg})\end{array}$} & \multicolumn{2}{|c|}{$\begin{array}{c}\text { Early preseason eccentric } \\
\text { strength }(\mathrm{N})\end{array}$} & \multicolumn{2}{|c|}{$\begin{array}{c}\text { Late preseason } \\
\text { eccentric strength }(\mathrm{N})\end{array}$} \\
\hline & & & Left limb & Right limb & Left limb & Right limb \\
\hline $22.6 \pm 3.3$ & $188.3 \pm 7.6$ & $87.8 \pm 7.6$ & $271.9 \pm 74.8$ & $290.8 \pm 84.4$ & $327.7 \pm 73.5$ & $336.9 \pm 71.0$ \\
\hline \multicolumn{7}{|c|}{ Previously injured group } \\
\hline \multirow[t]{2}{*}{$\begin{array}{l}\text { Age } \\
\text { (years) }\end{array}$} & $\begin{array}{l}\text { Height } \\
(\mathrm{cm})\end{array}$ & $\begin{array}{l}\text { Weight } \\
(\mathrm{kg})\end{array}$ & \multicolumn{2}{|c|}{$\begin{array}{c}\text { Early preseason eccentric } \\
\text { strength }(\mathrm{N})\end{array}$} & \multicolumn{2}{|c|}{$\begin{array}{c}\text { Late preseason } \\
\text { eccentric strength }(\mathrm{N})\end{array}$} \\
\hline & & & Injured limb & Uninjured limb & Injured limb & Uninjured limb \\
\hline $23.3 \pm 2.6$ & $186.2 \pm 6.5$ & $85.9 \pm 6.6$ & $309.3 \pm 91.2$ & $319.8 \pm 82.4$ & $311.2 \pm 78.1$ & $326.9 \pm 77.8$ \\
\hline
\end{tabular}

472 Data presented as mean \pm standard deviation.

473

474 
Table 3: Absolute and relative change in eccentric knee flexor strength across preseason for athletes with $(\mathrm{n}=17)$ and without $(\mathrm{n}=82)$ a history of hamstring strain injury in the prior 12 months.

\begin{tabular}{|c|c|c|c|c|c|c|c|c|c|}
\hline Group & Limb & $\begin{array}{l}\text { Absolute } \\
\text { change in } \\
\text { eccentric } \\
\text { strength }(\mathrm{N}) \\
\quad \pm \mathrm{SD}\end{array}$ & $\begin{array}{c}\text { Between limb } \\
\text { difference }(N) \\
(95 \% \mathrm{CI})\end{array}$ & $\mathrm{p}$ & Effect $\operatorname{size}^{\wedge}$ & $\begin{array}{c}\text { Relative change }^{\#} \text { in } \\
\text { eccentric strength } \\
\pm \mathrm{SD}\end{array}$ & $\begin{array}{c}\text { Between limb } \\
\text { difference } \\
(95 \% \mathrm{CI})\end{array}$ & $\mathrm{p}$ & Effect $\operatorname{size}^{\wedge}$ \\
\hline $\begin{array}{l}\text { Previously } \\
\text { injured }\end{array}$ & $\begin{array}{l}\text { Uninjured } \\
\text { Injured }\end{array}$ & $\begin{array}{l}14.7 \pm 54.0 \\
13.1 \pm 57.7\end{array}$ & $\begin{array}{c}1.6 \\
(-37.4 \text { to } 40.6)\end{array}$ & 0.88 & 0.03 & $\begin{array}{l}1.07 \pm 0.22 \\
1.07 \pm 0.18\end{array}$ & $\begin{array}{c}0.00 \\
(-0.14 \text { to } 0.14)\end{array}$ & 0.934 & 0.00 \\
\hline Uninjured & $\begin{array}{l}\text { Left } \\
\text { Right }\end{array}$ & $\begin{array}{l}60.7 \pm 72.9 \\
48.6 \pm 83.8\end{array}$ & $\begin{array}{c}12.1 \\
(-12.1 \text { to } 36.3)\end{array}$ & 0.06 & 0.15 & $\begin{array}{l}1.28 \pm 0.34 \\
1.24 \pm 0.43\end{array}$ & $\begin{array}{c}0.04 \\
(-0.08 \text { to } 0.16)\end{array}$ & 0.291 & 0.10 \\
\hline
\end{tabular}

${ }^{\#}$ Change determined as the quotient of the late over early pre-season eccentric hamstring strength. ${ }^{\wedge}$ Cohen's $d$ used to determine effect size. SD, standard deviation; 95\%CI, 95\% confidence interval. 
Table 4: Average absolute and relative change of both limbs in eccentric knee flexor strength across preseason for the athletes with ( $\mathrm{n}=17)$ and without $(\mathrm{n}=82)$ a history of hamstring strain injury in the prior 12 months.

\begin{tabular}{|c|c|c|c|c|c|c|c|c|}
\hline Group & $\begin{array}{c}\text { Absolute change in } \\
\text { eccentric strength }(\mathrm{N}) \\
\pm \mathrm{SD}\end{array}$ & $\begin{array}{c}\text { Between group } \\
\text { difference }(\mathrm{N}) \\
(95 \% \mathrm{CI})\end{array}$ & $\mathrm{p}$ & Effect size ${ }^{\wedge}$ & $\begin{array}{c}\text { Relative change } \mathrm{e}^{\#} \text { in } \\
\text { eccentric strength } \\
\pm \mathrm{SD}\end{array}$ & $\begin{array}{l}\text { Between } \\
\text { group } \\
\text { difference } \\
(95 \% \mathrm{CI})\end{array}$ & $\mathrm{p}$ & Effect si \\
\hline Previously injured & $13.9 \pm 55.0$ & & & & $1.07 \pm 0.20$ & & & \\
\hline Uninjured & $54.6 \pm 78.5$ & $\begin{array}{c}40.7 \\
\text { (1.0 to } 80.4)\end{array}$ & $0.012^{*}$ & 0.60 & $1.26 \pm 0.39$ & $\begin{array}{c}0.19 \\
(0.0 \text { to } 0.38)\end{array}$ & $0.015^{*}$ & 0.73 \\
\hline $\begin{array}{l}\text { Covariate effect } \\
\text { (early pre-season } \\
\text { eccentric strength) }\end{array}$ & & & $<0.001^{\sim}$ & & & & $<0.001^{\sim}$ & \\
\hline
\end{tabular}

